\title{
A 50 años de la furia del apu Huascarán
}

\author{
Artículos originales: ANTROPOLOGÍA \\ Recibido: 17/09/2020 \\ Aprobado: $16 / 10 / 2020$ \\ Publicado: 05/02/2021
}

\author{
Román Robles Mendoza \\ Universidad Nacional Mayor de San Marcos \\ hermanovallejo@gmail.com
}

\begin{abstract}
RESUMEN
Este trabajo relata la memoria de los acontecimientos ocurridos como consecuencia del terremoto que sacudió al departamento de Ancash el 31 de mayo de 1970. Hacemos un resumido recuento de la siniestrada ciudad de Huaraz y del pavoroso aluvión que sepultó a Yungay. Con los sobrevivientes de ese fenómeno telúrico, el gobierno central propició la emigración de familias damnificadas a la Colonización de Tingo María-Tocache-Campanilla. El relato concluye con la exposición de los resultados económicos y sociales de los colonos ancashinos asentados en Nuevo Paraíso y Santa Lucía.
\end{abstract}

PALABRAS ClAVE: terremoto de Ancash; traslado de damnificados; colonización de Tingo María; Nuevo Paraíso; Santa Lucía.

\section{Years after the fury of apu Huascarán}

\begin{abstract}
This work recounts the memory of the events that occurred as a result of the earthquake that shook the department of Ancash on May 31, 1970. We make a summary account of the sinister city of Huaraz and the terrifying flood that buried Yungay. With the survivors of this telluric phenomenon, the central government encouraged the emigration of families affected to the Colonization of Tingo María-Tocache-Campanilla. The story concludes with the presentation of the economic and social results of the Ancash settlers settled in Nuevo Paraíso and Santa Lucía.
\end{abstract}

KeYwords: Ancash earthquake; Transfer of victims; Colonization of Tingo María; Nuevo Paraíso; Santa Lucía. 


\section{Preámbulo}

D e acuerdo a la cosmovisión andina, los dioses montańa o apus tutelares, conversan, aman, ayudan, se enamoran, protegen, pero también se molestan y entran en cólera, de acuerdo al comportamiento de la gente con quienes interactúa. Por eso, los habitantes del entorno de los apus, deben estar siempre en armonía con sus deidades. Algunos mitos y leyendas explican muy bien el comportamiento de los apus montaña. Rodolfo Sánchez y Jürgen Golte (2014) han rescatado la leyenda del trágico romance del joven Sawasiray y de la nuusta Pitusiray en Cusco. Por escasez de agua por la sequía, el padre de Pitusiray ofreció la mano de su hija a quien haga llegar agua a sus tierras. Fue Kuntisiray quien logró la hazaña y se casó con la ñusta. Pero ella estaba enamorada perdidamente de Sawasiray. Huyen a las alturas y son perseguidos, alcanzados y transformados en dos montañas nevadas en Calca. Marcos Yauri (2000) ha visibilizado la leyenda sobre el origen del Huascarán en el Callejón de Huaylas. Relata el amorío que sostuvieron el joven Huáskar, hijo del conquistador cusqueño y de la princesa Wandy, hija del curaca del reino de Huaylas. Por la prohibición de su padre, los enamorados se veían en secreto, pero fueron descubiertos. Furioso, el padre de Wandy, por los amores pecaminosos de su hija con un enemigo cusqueño, mandó apresarlos y condenarlos a ser atados en las altas montañas. Allí sufrieron ambos el rigor del frío, la soledad y el llanto, pero el dios de Huaylas se compadeció de ellos y los convirtió en dos montañas nevadas. Wandy fue transformada en el nevado Huandoy y Huáskar en Huascarán, quienes se quedaron para siempre en la cordillera blanca. Con sus lágrimas se formaron las lagunas de Chinacocha, que derrama sus aguas para los agricultores del valle. De tiempo en tiempo estos apus entran en cólera por algún motivo y descargan su furia sobre sus dominios. "Ahora la gente ya no le hace pagos al nevado (Huascarán), por eso se molesta, enviándonos temblores y diluvios», opina una sobreviviente de Yungay.

\section{La honda sísmica del terremoto en Lunahuaná}

Ocurrió el domingo 31 de mayo del año 1970. Un terremoto de magnitud $7.9^{\circ}$ remeció al centro-norte del Perú, cuyo epicentro fue localizado a $44 \mathrm{~km}$ al suroeste del mar Pacífico, frente a Chimbote, a una profundidad de $64 \mathrm{~km}$. Sus efectos más destructivos se produjeron en el Callejón de Huaylas, donde se encuentra el nevado Huascarán, el macizo más alto de la cordillera de los Andes que atraviesa el territorio peruano. Ese día, «Huaraz presunción», capital del departamento de Ancash, quedó en escombros y "Yungay hermosura» fue arrasado por un violento aluvión que se precipitó del apu Huascarán. Personalmente sentí la onda sísmica, como un jugueteo de vaivén de una roca, en el interior del río Cañete, situado a más de $400 \mathrm{~km}$ del epicentro del sismo.

Vivía en Lima desde 1954. Ese domingo, habíamos salido de paseo familiar a Lunahuaná, en el valle de Cañete. Pasamos un hermoso día de sol, compartiendo amenamente con la familia a la que visitamos. Por la tarde, el anfitrión nos invitó a visitar sus plantaciones de frutales, donde comimos pacaes cogidos de la misma planta. Luego, fuimos al río a pescar camarones. Sin éxito en la pesca, subimos a una peña que estaba a unos diez metros dentro del río. Eran las $3.30 \mathrm{pm}$, cuando de pronto sentimos que la peña se movía. Cuando tratábamos de pararnos, vimos que de los cerros aledańos se desprendían piedras y tierra, levantando polvareda. Recién nos dimos cuenta que se trataba de un fuerte temblor. Saltamos de piedra en piedra para retornar a la casa; corrimos por un caminito que sale hacia la carretera, por medio de escombros de piedras que se habían caído al camino con el movimiento sísmico. Por información radial nos enteramos que el núcleo del terremoto se había producido en el departamento de Ancash. La honda sísmica se sintió con cierta intensidad en Lunahuaná, estando a más de $400 \mathrm{~km}$ del epicentro, afectando caminos y viviendas de adobe en el valle. Esa tarde retornamos a Lima. La carretera se encontraba transitable, con pequeños derrumbes de tramo en tramo.

\section{Alarma en la capital}

Esa noche y el día siguiente, los comentarios radiales propalaban sólo noticias del terremoto ocurrido en Ancash. Todo era noticia de alarma, de dolor humano, por las muertes y la destrucción de pueblos enteros. Daban cuenta de las continuas réplicas telúricas, 
que no cesaron por varios días. En todas las emisoras se difundían noticias de los efectos provocados por el terremoto, de pueblos en escombros, de caminos y carreteras afectadas, canales de riego enterrados y destruidos. Todos los programas se suspendieron para dedicarlos a la información que venía de Ancash, donde todo era muerte, dolor, desgracia. Se inició un enlace radial entre los migrantes ancashinos en Lima, con la colaboración de reporteros y sobrevivientes de los pueblos afectados. Muchos migrantes ancashinos se acercaban a las emisoras para comunicarse con las autoridades o sus familiares. Todos ellos querían saber sobre la situación de sus seres queridos allá en la tierra natal. Por varios días, las emisoras de radio se prestaron para intercomunicarse con la gente de la zona afectada por el terremoto. No era para menos, la naturaleza castigó despiadadamente a los pueblos del departamento de Ancash y provincias vecinas.

Alarmantes y dolorosas noticias se publicaron en la prensa escrita, desde el 1 de junio. Todos los periódicos de alcance nacional dedicaron sus portadas sobre el terremoto de Ancash. Las primeras planas de los diarios de Lima anunciaron así el acontecimiento: El Comercio: «Terremoto en el norte»; el diario Correo: "Destrucción en Callejón de Huaylas. Situación es dramática en Huaraz»; diario oficial El Peruano: "Los tres minutos que borraron Yungay»; diario la Crónica: «Es incalculable la devastación». Canales de televisión, emisoras de radio y periódicos cotidianos se ocuparon profusamente de la hecatombe telúrica durante varios meses de ese año. Durante las primeras semanas de junio, las noticias exclusivas eran acerca de la destrucción de pueblos, caminos y canales de riego, de las muchas muertes humanas, de la búsqueda de cadáveres en los escombros de las ciudades, de los primeros auxilios enviados por el gobierno central y por los gobiernos de distintos países del mundo. Continuaron con las noticias de cuerpos recuperados de los escombros, de la instalación de carpas y viviendas provisionales en todo el Callejón de Huaylas y otras regiones del departamento de Ancash; también sobre la llegada a Lima de ayuda humanitaria de países vecinos. Se reportaron también sobre la llegada de brigadas de ayuda médica humanitaria, como la que envió el gobierno de Cuba, con equipos de personal médico, materiales quirúrgicos y medicinas. Decenas de aviones aterrizaban en el Aeropuerto Jorge Chávez con ayuda material y cuantioso dinero, en apoyo al inmediato auxilio y la reconstrucción provocada por el sismo.

Desde el día siguiente del sismo, se produjo una avalancha de retorno de los migrantes ancashinos hacia sus pueblos de origen. La gente no se contentó con el enlace directo con sus familiares por medio de las emisoras de radio y los reportes de la televisión, pugnaban por llegar a sus pueblos para auxiliar a sus familiares en desgracia. Las agencias de buses se vieron abarrotadas desde el primer día. Los que iban a los pueblos de la sierra tuvieron dificultades insalvables durante la primera semana de junio, porque las carreteras de enlace de Paramonga a Huaraz, de Paramonga a Cajatambo y de Casma a Huaraz, estaban interrumpidos por derrumbes a lo largo de estos caminos. Frente a esa momentánea situación, muchos migrantes ancashinos residentes en Barranca, Huacho y Lima optaron por llegar a su tierra caminando, con sus bultos y maletas a la espalda. Las crónicas periodísticas de esos cruciales días, se ocuparon también de esas heroicas caminatas de mucha gente desesperada por ver a sus seres queridos en desgracia.

\section{Primer contacto con la realidad}

Me contagié de la valerosa actitud de mis coprovincianos. Con ese fin viajé a Barranca el miércoles 3 de junio, con la idea de internarme a mi pueblo de origen, Santiago de Chilcas, distante en $90 \mathrm{~km}$ y situado a 3,700 msnm, para encontrarme con mi familia. Busqué inútilmente alguna movilidad a Ocros o a Cajatambo. No salía ningún carro, porque estaban informados que la carretera estaba bloqueada por los derrumbes. No era el único pasajero varado en Barranca, éramos muchos y de distintos pueblos los que esperábamos viajar con cualquier movilidad. Estábamos parados en una esquina de la calle Comercio de Barranca, cuando se apareció un militar que nos hizo esta pregunta: ¿Alguno de ustedes conoce pueblos en las alturas del río Pativilca? Levanté la mano y contesté: «yo». Sin más diálogos, me invitó a subir a su camioneta y enrumbamos hacia la hacienda Paramonga que está al otro lado del río Pativilca. En el camino me explicó que en Paramonga esperaba un helicóptero para hacer un recorrido por algunos pueblos de la sierra, con la finalidad de detectar emergencias necesarias y llevar algo de víveres. Ninguno 
de los dos tripulantes del helicóptero conocía la ruta, por lo que necesitaban un guía. Me preguntaron qué poblaciones conocía; les dije que conocía a todas las localidades de las dos rutas río arriba. Se sintieron más confiados y animados por mi compañía. En efecto, conocía la mayoría de los distritos de la provincia de Bolognesi, situado al sur del departamento siniestrado, por haberla recorrido en mi primera juventud. También conocía a Cajatambo y a los pueblos de la minicuenca del río Rapay, por haberla visitado en 1968, por sugerencia del Dr. Pablo Macera, con motivo de los estudios sobre el quipu alfabético ${ }^{1}$, guardado en la iglesia de San Francisco de Mangas.

Esta magnífica oportunidad de viajar en helicóptero me cayó como del cielo, me sentí muy complacido hacer de guía a dos oficiales de la fuerza aérea. El helicóptero partió de Paramonga, rumbo al este. Volamos por encima del río Pativilca, mirando los paisajes de los cañaverales y algodonales de las ex haciendas de Paramonga, Otopongo y Huayto, convertidos ahora en Cooperativas Agrarias de Producción (CAP). Desde el helicóptero se podía mirar hacia todos lados por su estructura de vidrio ovalado. A medida que íbamos avanzando valle arriba, pude observar de cerca las tres montañas sagradas ubicadas entre la yunga y la quichua: cerro Corcovado, cerro Callau y Pusqanpunta ${ }^{2}$. Por primera vez pude mirarlos de cerca, por la altura que volaba el cóndor motorizado en que viajábamos. Cuando pasábamos por el cerro Corcovado, pudimos observar el pavoroso escenario provocado por el terremoto, cubierto de polvo, en el estrecho cañón rocoso que se bifurca hacia Cahua y Cajatambo y por el micro valle de Huanchay-Ocros. Les mostré desde la cabina la ubicación de las tres localidades posibles a visitar ese día: Ocros, Chilcas y Acas, pueblos cercanos uno del otro, situados entre 3,500 a 3,700 msnm.

Aterrizamos primero en Ocros, el distrito más importante de este lado de la provincia de Bolognesi. Tocamos tierra en una chacra de alfalfa recién cosechada. Alertados por el sonido del helicóptero, la gente venía por decenas hacia nosotros, en desesperada carrera. En cuestión de minutos se abalanzaron

1 Tablilla con los nombres de los comuneros de Mangas identificados por cordeles de colores, utilizado por los evangelizadores en el año de 1800.

2 Estos apus seguían siendo temidos y reverenciados por la gente de su entono y se contaban muchas leyendas sobre sus poderes y encantos. al interior del helicóptero para arranchar, sin permiso alguno, todos los sacos de víveres y medicinas que llevábamos para distribuirlos en los tres pueblos. Nada pudieron hacer los dos militares para impedir ese inesperado saqueo. Conversamos brevemente con algunas personas mayores que se acercaron al lugar y por ellos tuvimos información de los daños sufridos en los edificios públicos y viviendas familiares. Por ellos supimos que la antigua iglesia de Santo Domingo, de hermosa fachada exterior, se había derrumbado casi por completo. Asimismo, la carretera de Ocros hasta Rinconada se encontraba intransitable por los derrumbes que no cesaban con las constantes réplicas de temblores de menor intensidad. Informaron también que había varios heridos de poca gravedad. Mucha gente se había quedado en la calle por el derrumbe de sus casas de adobe, pero nadie había muerto. No entramos a la ciudad, los militares consideraron prudente salir de allí, muy incómodos por lo ocurrido con la turba de jóvenes.

Despegamos rumbo a Santiago de Chilcas, situada a sólo $15 \mathrm{~km}$ hacia el sur y a unos $200 \mathrm{~m}$ más de altura que Ocros. Aterrizamos en el campo de futbol, cerca de la población. Allí también la gente corría hacia nosotros, pero se quedaron mirándonos a cierta distancia. Cuando me reconocieron se sintieron más aliviados, pero se sorprendieron que llegáramos por el aire, con un aparato volador que nunca habían visto. Las autoridades de Chilcas nos invitaron a visitar al pueblo. Fuimos con uno de los oficiales. Recorrimos varias calles colapsadas por el derrumbe de paredes de viviendas familiares. Había que caminar con cuidado porque casi todas las casas estaban por los suelos. Adobes, tejas y calaminas yacían en las calles o en sus mismos lugares. En la plaza habían instalado chozas y carpas provisionales donde jugaban niños y niñas. Hombres y mujeres mayores se encontraban tratando de rescatar sus enseres debajo de los escombros; otros apuntalaban las paredes semiderruidas para habitarla momentáneamente. Todo era desolación, llanto y tristeza. Nos informaron que durante el terremoto habían muerto tres personas que ya habían sido enterradas. Quedaban varios heridos, dos de gravedad. Los militares ordenaron que les alisten a los dos heridos graves para conducirlos al hospital de Paramonga, con uno de sus familiares. Tuve tiempo de visitar mi casa, que también estaba en escombros. Ninguno de mis familiares sufrió daño. Fue una sa- 
tisfacción abrazarlos a todos, habiéndoles encontrado sanos y salvos. Les prometí volver pronto.

Cuando nos alistábamos para partir de regreso a Paramonga vimos que se acercaba un avión a baja altura. Pasó por encima del pueblo, dejando caer un bulto cubierto con frazadas. Cayó cerca de una casa, tocándole de refilón a una señora que se encontraba en la puerta. Fue fatal ese acontecimiento, porque la seńora murió al instante, por el impacto. La gente del pueblo se congregó en torno a la finada, pero ya nada se podía hacer. El oficial se acercó al cuerpo yaciente y comprobó que ya estaba sin vida. Una desgracia más sobre la tragedia del terremoto. Las autoridades del pueblo desataron el bulto para ver su contenido. Encontraron 20 frazadas y cerca de 80 tapers de comida cocinada. En esos momentos había en ese ambiente dolor por la muerte accidental de la señora y alegría por los platos de comida que el gobierno central arrojaba en todos los pueblos afectados. El militar ayudó a organizar el reparto de la comida ordenadamente, principalmente a niñas, niños y mujeres. Días más tarde, nos enteramos por los medios de prensa, que otro avión, que hacía el mismo servicio de auxilio con frazadas y víveres, se precipitó en un cerro cerca de Cajacay, en el valle del Fortaleza. Cuando eran ya las $4.30 \mathrm{pm}$, levantamos vuelo de regreso a Paramonga, transportando a los dos heridos y sus familiares. Los heridos fueron internados en el hospital y dos meses después, nos enteramos que habían retornado a Chilcas, en mejores condiciones de salud.

Campaña de ayuda. En las semanas siguientes, iniciamos una etapa de ayuda a la tierra de nuestros orígenes. Nos organizamos colectivamente, bajo la conducción de la Asociación Unión Regional Chilcas (AURCH), institución que agrupa a los migrantes de mi pueblo en Lima. Hicimos una recolección de víveres no perecibles, ropa, cobertores, utensilios de cocina y diversos enseres necesarios para llevarlos a Chilcas. Cada quien aportó voluntariamente con lo que podía. En pocos días se juntó buena cantidad de objetos, que fueron acopiados en dos puntos, donde residía la mayoría de chilcasinos. Transportamos lo recolectado a Barranca, para luego contratar un camión y llevarlo a su destino final. Para entonces habíamos comunicado a las autoridades para que se apersonen con sus acémilas hasta el lugar de los trabajos de reparación de caminos. Eso hicimos. El día fijado viajamos hasta Huaylías, a $45 \mathrm{~km}$ de
Paramonga, con nuestra carga de ayuda humanitaria; más allá no había pase, los trabajadores del Ministerio de Transportes se encontraban trabajando arduamente para habilitarlas. Tuvimos que esperar, junto con varios grupos de migrantes que hacían lo mismo que nosotros: llevar materiales de auxilios a sus pueblos de origen. La comisión de la comunidad de Chilcas llegó a las ocho de la noche con varias acémilas. A ellos les entregamos lo que habíamos llevado y con ellos pasamos esa noche en la repartición de Huaylías, asediados por los insoportables zancudos. Al día siguiente, retornamos a Barranca y a Lima.

Nuestro entusiasmo por seguir colaborando con las familias de nuestro pueblo no se detuvo, nos enfrascamos con la segunda campaña. Colaboraciones voluntarias de nuestros paisanos, agregando además los aportes de instituciones, casas comerciales y empresarios, que estaban sensibilizados con lo ocurrido en Ancash. Acopiamos otra cantidad de víveres y otros menesteres para transportarlos hasta Barranca, ciudad que servía de puerto para todos los pueblos de esta región del norte chico. Esta vez viajamos a fines de junio sólo dos personas. En Barranca nos enteramos que la carretera ya estaba habilitada hasta Pampa Laguna, a sólo $8 \mathrm{~km}$ de Chilcas. Igual que en la primera campańa, esta vez también contratamos un camión, que nos transportó hasta Pampa Laguna donde nos esperaban las autoridades y un buen grupo de comuneros. Nos recibieron con mucha alegría. Con ellos nos dimos emocionados abrazos de reencuentro en plena desgracia. Se notaba que los ánimos de la gente se habían apaciguado, la solidaridad de sus hijos de la AURCH les daba mayor entusiasmo para paliar la desgracia sufrida. Después de hacerles entrega de la colaboración institucional y hacer la necesaria millcapa, retornamos a pie. Pernoctamos en el camino y al día siguiente caminamos hasta Huanchay. Tuvimos suerte, una familia con auto nos transportó generosamente hasta Barranca.

\section{En el epicentro del terremoto y del aluvión}

Un inesperado acontecimiento me involucró con mayor profundidad al problema del terremoto y el aluvión de Ancash. Ocurrió en los primeros días de julio de 1970, cuando el Dr. Mario Vásquez Varela, jefe de la Dirección de Comunidades Campesinas del 
Ministerio de Agricultura me convocó a su oficina en Jesús María. Dos años antes, Mario Vásquez, había sido mi profesor de antropología aplicada en San Marcos, después de su destacada labor en el Proyecto Perú-Cornell, aplicado en la comunidad de Vicos en el Callejón de Huaylas. Me pidió que colabore con él en asuntos urgentes de ese ministerio. Me planteó dos propuestas: primero, que le ayude a convocar veinte estudiantes o egresados de ciencias sociales; segundo, que yo escoja uno de tres opciones de trabajo en la selva: Genaro Herrera, Pucallpa o Tingo María. Me explicó lo que se debe hacer en cada lugar mencionado. Sin pensarlo dos veces, tuve que decidir por el de Tingo María, porque consistía en trasladar familias damnificadas por el terremoto de Ancash hacia la colonización del alto Huallaga. Cumplí con enviarle los veinte egresados y estudiantes. Personalmente me sentí muy complacido por involucrarme en un programa de apoyo a los damnificados de mi departamento. Así comenzó la segunda etapa de mi contacto con la realidad social de Ancash, afectada por el terremoto.

Fuimos convocados al local de la Junta de Asistencia Nacional (JAN), en Pueblo Libre. Allí se realizó una reunión con representantes de varias instituciones, para tomar acciones sobre el traslado de damnificados a la selva de Tingo María. La presidió un asesor de la Primera Dama de la Nación, señora María Consuelo Gonzales Posada de Velasco, presidenta de la JAN. Estuvo presente el Dr. Mario Vásquez, delegados de Cáritas y de Ofasa, representantes de instituciones del Estado: Ministerio de Transportes y Comunicaciones (MTC), Dirección de la Oficina Nacional de Desarrollo Comunal, Comisión Nacional de Apoyo Alimentario. Allí conocí a Alberto Irigoyen, con quien trabajaría en el proceso de motivación para el traslado de campesinos a la selva. Nos dieron a conocer los detalles del proyecto, las responsabilidades que asumirían las diversas instituciones. También nos informaron el diseño general del proyecto de traslado de damnificados. Comprendería tres fases: a) motivación, inscripción y traslado de familias a Tingo María, b) aclimatación previa de las familias por tres meses en el campamento de Zangapilla (Aucayacu) y c) traslado y entrega de lotes de tierra a cada familia en el sector de Megote. La tercera fase del proyecto estaría a cargo de la IX Sub Zona Agraria, con sede en Aucayacu, que era al mismo tiempo, sede de la Colonización de Tingo María-Tocache-Campanilla, un programa nacional financiada por el (BID) ${ }^{3}$. A partir de esta reunión conjunta, el proyecto de traslado se echó a andar.

La siguiente reunión fue propiamente operativa, entre el Dr. Mario Vásquez, don Alberto Irigoyen y el suscrito. A esta reunión se sumó el chofer de la camioneta de doble cabina, proporcionada por el MTC, quien nos acompañó durante todo el proceso de traslado a Megote. Aprobamos un programa de ejecución del proyecto, que tendría dos fases: promoción e inscripción de familias damnificadas en Huaraz y Yungay y hacer lo mismo en pueblos de la provincia de Bolognesi. En esta primera fase participaríamos sólo con Irigoyen, con el apoyo del chofer asignado; en la segunda fase se agregarían dos personas más: la asistenta social señorita Sonia y la educadora familiar señorita Ofelia. La dirección ejecutiva del traslado correría a cargo de Alberto Irigoyen. Conversando con él me enteré que era natural de Ocros y que había sido por un tiempo, administrador de la hacienda de Llipllipa, la única que existía en esa comunidad. Era un hombre blanco, con bigotes, de contextura mediana alta, comunicativo y de decisiones inmediatas. Usaba un gorro al estilo siciliano. Congeniamos bien, por ser de pueblos vecinos de la entonces provincia de Bolognesi ${ }^{4}$.

\section{Entre Huaraz, Carhuaz y Yungay}

El 15 de julio salimos rumbo a Huaraz, epicentro del terremoto. Para entonces, la carretera afirmada de Paramonga a Conococha, ya estaba transitable hasta Huaraz. A lo largo del camino pudimos observar varios pueblos parcialmente siniestrados: Barranca y Pativilca mostraban muchas casas derrumbadas y con escombros en sus calles. Siguiendo el camino, vimos los destrozos en Chasquitambo, Cajacay, Ticapampa, Recuay y Cátac. Llegamos a Huaraz por la tarde, encontramos una ciudad en escombros.

Conocía los pueblos del Callejón de Huaylas por haberlos visitado antes del sismo. Tenía un idílico

3 El gobierno peruano firmó en 1966, el contrato de préstamo de BID para el financiamiento de la naciente Colonización de Tingo María-Tocache-Campanilla.

4 La provincia de Bolognesi fue creada en 1903. Su amplio territorio se dividió en 1990, al crearse la nueva provincia de Ocros. 
recuerdo de este valle, de varias poblaciones de climas distintos, frío en Recuay y Cátac, semifrío en Huaraz y Carhuaz y templado en Yungay y Caraz. La cordillera blanca, de extraordinario brillo en el verano, parecía una hermosa muralla para el Callejón de Huaylas, el río Santa su vena principal. Cada pueblo del valle era típico con sus plazas enlozadas, palmeras y jardines, tiendas de diversos negocios, casas techadas con teja labrada, algunas de ellas con balcones de madera. En todas ellas destacaba la iglesia cristiana, de dos altas torres en Huaraz y Carhuaz y de una sola torre en Yungay. Se podía degustar buena comida en todos estos pueblos: buen caldo de panza de res con mote de maíz pelado, mazamorra de tocosh y otros platos típicos. Para disfrutar el delicioso helado artesanal, había que ir a Carhuaz «borrachera», $30 \mathrm{~km}$ río abajo; y para degustar dulces de manjarblanco había que avanzar hasta Caraz «dulzura». Cada pueblo tenía su encanto particular. Era un valle que invitaba a vivir, por sus hermosuras y sus variados climas, de manera preferente Yungay «hermosura» de atractivas campiñas, donde nació la cantautora andina Angélica Harada, la «Princesita de Yungay».

Al llegar a Huaraz tuvimos un frustrante impacto visual. Hicimos un primer recorrido por el centro de la ciudad para observar en directo los efectos de movimiento telúrico. Casi todos los edificios públicos y las casas familiares estaban por los suelos. La catedral y sus torres también. Las típicas callecitas angostas que caracterizaban a Huaraz, habían desaparecido, sus restos eran sólo montones de adobes, tejas y maderas siniestradas. La gente circulaba con dificultad por pasajes provisionales abiertos entre los derrumbes acumulados en las calles. Varias casas se habían caído sólo parcialmente, dejando al descubierto sus ambientes interiores de dos o tres pisos. Todo era desolación y destrucción provocado por la furia de la naturaleza. Las montañas níveas seguían brillando hacia el lado este, pero los pueblos del Callejón, construidos en varios siglos de existencia, habían sido borrados en un solo minuto el 31 de mayo. Luego de haber caminado algunas cuadras de la ciudad destruida, quedamos totalmente impresionados por tanta destrucción. Los pobladores que se salvaron de la hecatombe, ya no lloraban después de casi dos meses de lo ocurrido, pero seguían buscando entre los escombros los restos aun no encontrados de sus familiares y de sus bienes sepultados. Con máquinas pesadas y volquetes comenzaban a despejar los desmontes acumulados, en medio de espesa polvareda.

No había alojamiento para hospedarnos, por lo que tuvimos que pasar la noche sentados dentro de la camioneta. Al día siguiente tomamos breve contacto con algunas autoridades, el alcalde y el prefecto, a quienes le informamos el propósito de nuestra presencia en Huaraz. Estaban muy atareados con los problemas de los heridos, de las familias sin hogar, en seguir removiendo los escombros para buscar cadáveres sepultados y limpiar las calles con personal contratado. El alcalde manifestaba que en esos momentos no había las condiciones para convocar a una reunión de familias afectadas. Nos pidió que le demos un par de días para realizar esa reunión. Tuvimos que aceptar la opinión del alcalde. Nos pusimos de acuerdo para que se convoque la reunión dentro de tres días.

Al día siguiente, viajamos a Yungay, localidad arrasada por el aluvión. La carretera que une a los pueblos del Callejón estaba plenamente habilitada, Al pasar por Ranrahirca y llegar a Yungay, pudimos observar con asombro, el estado en que habían quedado estas dos poblaciones. El aluvión se había precipitado por encima de las tres cuartas partes de Yungay, dejando a su paso una gruesa capa de lodo ya endurecida, dejando sólo una pequeña parte del pueblo en el lado norte. Quedaba en pie el Cristo en la cima del cementerio y los dos últimos pisos de nichos que lo circundan; los pisos inferiores de los entierros se los había llevado el huayco. En medio del lodo endurecido quedaban en pie cuatro palmeras, indicando que en ese lugar estaba la típica plaza yungaína, con su iglesia de una torre incorporada a la fachada del edificio. Desde Yungay se veía con claridad la huella de la cornisa desprendida del lado oeste del Huascarán. Se veía también la trayectoria del aluvión que, al precipitarse con tal violencia, rebasó la zanja del río que viene de Llanganuco, en una ola gigante hacia la población de Yungay y la otra rama del aluvión siguió el curso del río, desbordándose hacia Ranrahirca, hasta llegar al cauce del río Santa. Quedamos profundamente impresionados al mirar ese desolador panorama, a solo cincuenta días del terremoto.

En Yungay tuvimos mejor acogida para nuestro trabajo. Ese mismo día organizamos la primera reunión con los sobrevivientes, con el apoyo de autorida- 
des y personas entusiastas. Don Alberto se encargó en exponer el objeto de nuestra visita, al mismo tiempo que lamentó lo ocurrido en esa localidad y alcanzarles el pésame por los miles de yungaínos sepultados por el aluvión. Constaté que don Alberto era un buen orador, claro en sus objetivos y convincente en su discurso al describir las bondades de la Colonización de Tingo María. A mí me tocó complementar informaciones para incentivarles a que se animen a viajar a la selva, junto con sus familias más cercanas y reconstruir sus vidas, con el apoyo del gobierno. Tuvimos éxito en Yungay. En las dos reuniones que tuvimos con ellos se inscribieron más de 80 familias. En la ficha de inscripción figuraban los nombres de cada unidad familiar: padre, madre, hijos, con sus nombres completos, sus edades y género. Allí mismo les informamos la fecha que pasaríamos a recogerlos, para viajar primero a Lima y luego embarcarnos hacia Tingo María. Les informamos que todos los costos del viaje: transporte, comida, vestidos, ropa de cama, herramientas y estadía de tres meses de aclimatación, estaban garantizados por el gobierno y las instituciones de apoyo. Todo quedó debidamente coordinado en Yungay.

Pasamos un día en Carhuaz con el mismo propósito. Coordinando con las autoridades logramos tener una reunión con un grupo de damnificados, también afectados por el terremoto. Como en Yungay, les expusimos el objeto de nuestra presencia, por encargo del gobierno militar de entonces. Habiéndoles hecho una descripción del programa de traslado a la Colonización de Tingo María, les pedimos que se inscriban las personas que, voluntariamente desearan trasladarse a la selva, para construir un nuevo porvenir para sus familias. Se inscribieron doce personas, con los que acordamos que vendríamos en agosto para trasladarnos a Lima y luego a la selva de Tingo María.

En Huaraz logramos finalmente organizar una reunión con un pequeño grupo de damnificados, convocados por las autoridades de la ciudad. Les expusimos sobre los objetivos y detalles del programa de traslado hacia la Colonización de Tingo María, a todas las familias que voluntariamente se inscriban, por haber perdido sus viviendas y sus canales de riego y ser damnificados por los efectos del terremoto. Les dimos a entender que era un programa promovido por el gobierno, como una alternativa para rehacer sus vidas en un nuevo espacio, con todo el apoyo que les ofrece el Estado. El alcalde y el prefecto, contribuyeron también en alentar a que se adscriban al proyecto. Algunos asistentes plantearon preguntas, a las que respondimos como corresponde, pero pocos se animaron a inscribirse. Algunos asistentes manifestaron que lo pensarían mejor para otro día, consultando con sus familiares. Anotamos los nombres de todos ellos y les comunicamos que volveríamos en la segunda quincena de agosto, con la movilidad para trasladarlos, si es que hasta esa fecha se habían decidido a viajar.

\section{En los pueblos del sur de Ancash}

En la segunda semana de agosto hicimos el segundo viaje de promoción para el traslado de damnificados. Esta vez lo hicimos a pueblos de la provincia de Bolognesi, que Albero y yo conocíamos mejor. Se sumaron dos personas más al grupo: Sonia y Ofelia. Las dos señoritas eran de origen selvático, Sonia de Iquitos y Ofelia de Tingo María. Con una comitiva de cinco personas, viajamos a Ocros, Chilcas y Huanchay. Alberto Irigoyen conocía bien a la gente de Ocros. Eso facilitaba para el éxito de nuestra visita. Además, los efectos del terremoto no fueron muy destructivos allí, se cayeron más del $40 \%$ de las viviendas más débiles, con la iglesia colonial de por medio. Con el apoyo de las autoridades de la comunidad y del municipio tuvimos satisfactoria reunión de promoción en este distrito. Después de nuestras exposiciones se inscribieron cerca de treinta familias, estimulados por promotores conocidos por ellos. En Chilcas tuvimos igual bienvenida. La mayoría de las familias vivía en carpas y chozas instaladas en la plaza. Nos alojaron en una carpa donde pasamos la noche. A Sonia le dio el soroche. La gente muy atenta con los huéspedes, la atendió muy bien, trayéndole diversos remedios caseros en infusión y emplasto de chincho molido. Se reanimó con el calentado conocido como chinguirito, preparado con ron y yerbas de la puna. Por la noche nos visitaron con música de arpa y cantantes mujeres, con quienes nos alegramos por un buen rato. Hasta Sonia se levantó a bailar un huayno con el presidente de la comunidad. Al día siguiente, hicimos la exposición del proyecto de traslado, en la plaza pública. Se inscribieron cerca de veinte 
familias, entusiasmadas por nuestra presencia y por las bondades que ofrecía el proyecto.

Cuando retornábamos a Lima, nos detuvimos en Huanchay para almorzar. De pronto nos vimos rodeados por personas que querían inscribirse en la campaña de traslado de familias a la selva. Huanchay no estaba considerado en nuestro cronograma porque era un pequeño pueblo de agricultores y ganaderos pudientes, pero por la inesperada insistencia, tuvimos que aceptar sus deseos. Con evidente entusiasmo, se inscribieron más de quince familias, decididos a formar parte de los damnificados para viajar a la selva. Los incluimos, teniendo en cuenta que casi todos habían perdido sus viviendas, pero sus canales de riego y sus chacras se encontraban en buen estado. En esos días se instaló en Huanchay un equipo de médicos voluntarios cubanos, para atender a los damnificados de esa región. Con este nuevo contingente, teníamos suficiente número de inscritos para esta primera campaña. Regresamos a Lima con alentadora información.

\section{Marcha de damnificados a Tingo María}

Se inició el proceso de traslado del primer grupo de damnificados a la Colonización de Tingo María. Nos organizamos en dos grupos para recoger a la gente inscrita en los pueblos del Callejón de Huaylas y pueblos de la provincia de Bolognesi. Esa operación se cumplió en la tercera semana de agosto, con buses contratados por el MTC; la JAN proporcionó los fondos necesarios para cubrir los costos del traslado hacia Lima. Con la asistenta social viajamos primero a Ocros. Con la colaboración de Julio Alzamora, recogimos a las familias inscritas en ese distrito. En Chilcas nos esperaba el grupo de familias inscritas, que subieron al bus con sus enseres necesarios. De bajada a Barranca hicimos escala en Huanchay para hacer la misma operación, con la gente que decidió hacer esa aventura hacia la selva. Con todos ellos llegamos a Lima por la noche. La JAN los alojó en su amplio local de Pueblo Libre y les sirvió sus alimentos. El grupo del Callejón de Huaylas, también llegó ese día por la noche y se alojaron en el mismo local.

Con buses interprovinciales, partimos con destino a la Colonización, el 28 de agosto. La comitiva que acompańó a los damnificados aumentó en nú- mero, además de nosotros cuatro, se unieron el médico y dos representantes de Ofasa, encargados de la asistencia médica y de la alimentación. Sonia, que iba conmigo en el mismo bus, no resistió pasar la altura de Ticllo, le volvió a dar el soroche. Con la atención del médico pudo resistir hasta Huánuco, para ser internada en el hospital por dos días. Nos quedamos todos en Huánuco ese día, para emprender el último tramo del viaje al día siguiente. El programa de traslado había previsto alojar a los damnificados en el campamento del MTC en Zangapilla, situado a 50 km de Tingo María, cerca de Aucayacu. Los damnificados se ubicaron en dos grandes galpones y nosotros cuatro ocupamos una casita de tres ambientes, frente a los galpones, cerca de un pantanal, que nos permitiría disfrutar por tres meses, de croantes conciertos matutinos y vespertinos de numerosas ranas.

\section{Plan de aclimatación}

Allí nos quedaríamos los meses siguientes, para aclimatar a la gente de la sierra, en un nuevo ambiente tropical de sofocante sol y abundantes bichos que picaban a los recién llegados. Con nuestra llegada, Zangapilla se convirtió en una nueva población. Nuestra presencia llamó la atención de la gente de Aucayacu, especialmente por ser gente damnificada por el terremoto de Ancash. Nuestro campamento estaba situado fuera de la población, no interfería la vida normal de los lugareńos. A pocos metros del campamento pasaba la carretera marginal, que recorría de Tingo María hasta Tocache, más de $172 \mathrm{~km}$. $\mathrm{Al}$ costado del campamento estaban las instalaciones de una piladora de arroz, en ambiente cerrado, regentada por un sacerdote inglés, que prestaba servicios a los agricultores de todo el valle del Alto Huallaga. En esas instalaciones vivían jóvenes alemanes del «cuerpo de paz». Teníamos un vecindario de extranjeros.

Desde nuestra llegada al campamento comenzamos a acomodarnos bien en el espacio disponible. Sonia y Ofelia se dedicaron a organizar la cocina para que las mismas madres de la delegación se encargaran de preparar los alimentos. Los dos apoyos de Ofasa se dedicaron a organizar mejor la separación de ambientes dentro de los galpones, entregar colchones, frazadas y ropa usada a cada familia, según el número de sus miembros. Don Alberto y yo nos dedicamos 
a buscar agua para preparar los alimentos, con varios jóvenes de la delegación. La gente del lugar nos ayudó a ubicar un arroyo a $1 \mathrm{~km}$ de distancia. De allí trajimos agua en baldes, internándonos por el bosque. Este arroyo se convirtió a partir de esos días en piscina refrescante, en sus pozos de aguas cristalinas. Durante los días siguientes, hicimos un camino hacia el arroyo, con la fuerza de trabajo de la misma gente. Aprendimos a utilizar el machete, como herramienta básica, tanto para abrir camino en la tupida selva como para la defensa contra los ofidios. Desde ese día establecimos turnos para el acarreo de agua del arroyo al campamento. Las mujeres, bajo la supervisión de la asistenta social y la educadora familiar, se adaptaron muy bien en la preparación del desayuno, almuerzo y cena. Se hicieron populares las «cachangas», preparadas con harina, fritas en aceite. Una tribuna deportiva de madera, nos sirvió de mesa para degustar los alimentos, con atención especial a niños y niñas de las familias damnificadas. Establecimos un cronograma de actividades diarias, para varones, mujeres y niños. Consistía en ofrecerles charlas sobre diversos temas. Sonia y Ofelia se dedicaban a atender al grupo de señoras, niños y niñas, dándoles charlas, cursillos sobre comportamiento social, higiene, curación de enfermedades. Zangapilla se convirtió por todo esto en una escuela de información básica para los damnificados.

Conociendo la región. En las siguientes semanas nos dedicamos a conocer el entorno de nuestro hogar de Zangapilla. Visitamos al campamento de la Colonización de Tingo María-Tocache-Campanilla, que al mismo tiempo era la sede de la IX Sub Zona Agraria, con fines de la reforma agraria. Estaba cerca. Fuimos recibidos por su director, el Ing. Pavlikovski y los ingenieros de su equipo de trabajo. Dio la bienvenida a los damnificados, lamentando por las muchas vidas perdidas y las poblaciones siniestradas por efecto del sismo y del aluvión de Yungay. Nos dijo que la Zona Agraria a su cargo brindará todo el apoyo necesario para ubicar a los damnificados en el lugar ya designado, que estaba siendo acondicionado para ubicarlos. Nos presentaron a los ingenieros responsables de áreas de trabajo y al personal administrativo, entre los que se encontraban, una asistenta social y dos abogados sanmarquinos. Enseguida nos hizo conocer las oficinas y todo el campamento. Tuvimos tiempo de conocer a la población de Aucayacu, ca- pital del distrito José Crespo y Castillo, situado cerca de las oficinas de la Colonización. Era un pueblo situado en un recodo del río Huallaga, con una calle principal donde estaban el municipio, la comisaría, el mercado de abastos y tiendas de negocios; en las calles transversales se ubicaban las viviendas de las familias residentes allí.

Conocimos también Tingo María, capital de la provincia de Leoncio Prado, miramos de allí a la «Bella durmiente»; visitamos al centro experimental de cultivo de plátanos de Tulumayo, dirigido por el padre de Ofelia, y al campamento de SAIPAI, fundado por migrantes italianos. Recorrimos también varias poblaciones, valle abajo del Huallaga, que va de sur a norte. Organizándonos en grupos; viajamos a Madre Mía, Puerto Progreso y al entonces distrito de Tocache ${ }^{5}$, de la provincia de Mariscal Cáceres, departamento de San Martín, que está a 120 km de Aucayacu. Para llegar a Tocache había que pasar en canoas, de la margen derecha a la margen izquierda, luego subir los 103 escalones para llegar a la población. Tocache era una localidad de numerosa población, con su plaza central, varias calles, con oficinas de las autoridades locales y de empresas, como de la palma aceitera, productores de cacao, coca y café. Los amplios cultivos de palma aceitera los conoceríamos en los meses siguientes. No pudimos llegar al distrito de Uchiza, porque esa población está al otro lado del río y suponía hacer un viaje especial. Conocimos con nuestra gente, las principales poblaciones del valle, de las provincias de Leoncio Prado y de Mariscal Cáceres, de Huánuco y San Martín, desplazándonos por la carretera marginal.

Surcando el río Huallaga. En octubre tuvimos nuestra primera experiencia de surcar en el río. Elegimos un grupo de damnificados de distintos pueblos, para hacer la primera visita al futuro asentamiento de Megote, cerca del río Frijol, tributario del Huallaga. Para tal efecto, coordinamos con las autoridades de la Sub Zona Agraria, quienes se encargaron de proveer la movilidad de Zangapilla a Puerto Progreso, surcar $5 \mathrm{~km}$ del río Huallaga y de allí tomar una carreta tirada por un tractor hasta Megote, otros tres $\mathrm{km}$ bosque adentro. Para todos los damnificados fue una novedad surcar el Huallaga, deslizándonos

5 Tocache alcanzó la categoría de capital de provincia, al crearse la provincia, el 6 de diciembre de 1984. 
río arriba. En el lugar indicado nos esperaba el tractorista, quien nos condujo hasta el campamento de Megote. Estaban haciendo un galpón grande de unos quince metros de largo y seis metros de ancho, con maderas cruzadas y techo de palmeras secas, además de otros ambientes de menor tamaño para albergar a las familias, la posta médica y el personal administrativo, que conformábamos seis personas.

Inauguramos el galpón mayor, almorzando allí con los fiambres que llevábamos. Después de la mishquipa, la delegación de visitantes recorrió los alrededores del campamento. Todos pudimos ver cómo los técnicos habían abierto espacios para construir la carretera de penetración y el campamento, tumbando gigantescos árboles de un terreno plano cubierto de espeso bosque. La carretera doblaba en un ángulo de 90 grados hacia el oeste. Era el camino que conducía a los lotes de tierra para la agricultura, que se entregaría a cada familia damnificada. Por esta visita organizada, los campesinos de Ancash tomaron contacto directo con lo que sería en adelante su nueva estancia. Varios comentaron sobre las charlas de desbosque que le habíamos ofrecido en Zangapilla, haciendo preguntas al ingeniero de la Zona Agraria que nos acompañaba. Uno de nuestros anfitriones nos condujo al río Frijol, a sólo 200 m del campamento. Con mucha alegría vimos que por ese riachuelo discurría poca agua, cristalina, formando allí una gran poza. Todos nos lanzamos al agua para refrescarnos del calor sofocante. A los campesinos les encantó tomar contacto con un río tranquilo y cristalino, tan cerca del campamento, por lo que no tendrían dificultades para acarrear agua dulce y tener un bañadero casi al borde de sus viviendas. Muy contentos por haber conocido la ubicación del futuro pueblo, retornamos por la tarde a Zangapilla, esta vez, deslizándonos en canoas con motor fuera de borda hasta puerto Progreso y de allí hacia Aucayacu.

\section{Rumbo a la «tierra prometida»}

Llegó ese esperado día. En la primera semana de diciembre nos fuimos a Megote con todos los damnificados ancashinos. Fue todo un acontecimiento retirarnos de Zangapilla, con buses de la Sub Zona Agraria, responsable del asentamiento de campesinos dentro del proyecto de la colonización. Llegamos a
Megote al mediodía, habiendo surcado por grupos el río Huallaga, trasladándonos luego en un volquete y en una carreta tirada por una pala mecánica. Cuando arribamos a Megote, el campamento ya estaba concluido en sus instalaciones y la carretera de penetración había sido enripiada. La mayoría de la gente llegó a este lugar por primera vez. Se sorprendieron por el pueblecito recién construido en medio de una selva espesa. Ellos se sintieron satisfechos por los acabados de la casa comunal y de las casas familiares levantadas en el perímetro del campamento. Con el apoyo del personal de la colonización, procedimos a distribuir las viviendas familiares, priorizando espacios grandes a familias con mayor número de miembros; a los jóvenes sin familia los ubicamos por grupos en viviendas colectivas. El enfermero que viajó con nosotros tomó posesión del ambiente destinado para posta médica, con un ambiente para su vivienda. Después del almuerzo, hicimos conocer a todos el río Frijol. Los nińos y nińas se metieron a la poza de inmediato, para disfrutar del baño fresco, que ya habían experimentado en el arroyo de Zangapilla.

Nuevo Paraíso. Nuestra primera reunión en la casa comunal tuvo lugar el siguiente día del arribo a Megote. Fue una sesión muy amena, donde intervinieron varias personas, mostrando la satisfacción por haber llegado a la «tierra prometida», como lo llamaron ellos. Nos pusimos de acuerdo con el ingeniero encargado y los damnificados, sobre la distribución de lotes de terreno para cada familia. La mayoría de campesinos estaban inscritos para recibir un lote para cultivar; otro pequeño grupo estaba inscrito para implementar ganadería. Lo haríamos primero en el croquis y luego hacerles entrega personal y señalización de las parcelas, uno a uno, en el mismo terreno. Asimismo, por acuerdo de las señoras, la cocina seguiría funcionando como en Zangapilla, por el sistema de olla común, servido en la casa comunal. Surgieron allí varias ideas y propuestas. El señor Ángeles de Yungay sugirió ponerle un nuevo nombre al campamento. Se presentaron varias propuestas que provocó una larga discusión. El profesor Morales de Raján propuso el nombre de Nuevo Paraíso. La mayoría aplaudió la propuesta y por votación quedó acordado, que en adelante se llamaría Nuevo Paraíso.

Entrega de tierras. Los días programados para la entrega de terrenos, nos dirigimos a la zona de tierras agrícolas seńalada por los técnicos. Un ingenie- 
ro y varios extensionistas se encargaron de ubicar y señalizar las parcelas de 10 ha a cada colono. Para esta operación tenían que adentrarse al espeso bosque para dejar señales con pintura sobre el tallo de los árboles. El ingeniero se encargaba de hacer firmar las actas de entrega, con los datos de cada damnificado. Concluida la entrega de parcelas a los agricultores se procedió hacer la misma operación con los aspirantes a ganaderos, que recibieron parcelas de 40 ha, cuyos terrenos estaban a mayor distancia, pasando el río Frijol $^{6}$. Ese trabajo de distribución de lotes tomó una semana, pero se ejecutó conforme estaba previsto en el programa de promoción de traslado a los damnificados de Ancash. El ingeniero de la Sub Zona Agraria sugirió que cada familia haga su vivienda en la misma parcela, para facilitar el trabajo de desbosque, limpieza de terreno y sembrío. Nosotros propusimos que esa operación se realice gradualmente, teniendo como base la vida comunitaria en el campamento de Nuevo Paraíso. Durante las semanas siguientes se iniciaron los trabajos individuales en las mismas parcelas, sólo algunos hicieron sus casitas en el borde de sus lotes, pero no se trasladaron a vivir allí. En cambio, los ganaderos, se trasladaron en grupo a sus terrenos, dos semanas después. Este grupo estaba formado por damnificados de Huanchay, mucho más familiarizados en crianza de ganado vacuno. Hasta allí, todo bien.

Primeros obstáculos. Las dificultades para los damnificados aparecieron en el manejo de las parcelas, otorgadas en propiedad. Por primera vez se enfrentaron con lo que significa cultivar la tierra en la selva, que es diametralmente distinta que cultivar en la sierra. El primer escollo era derribar gigantescos árboles del bosque, de más de tres metros de espesor, con raíces extendidas en varias direcciones. Seccionarlos, esperar que se sequen, juntar las ramas en un solo lugar para quemarlos, es el siguiente paso. Ese tipo de trabajo sólo podía hacerlo un especialista, utilizando sierra mecánica, lo cual tiene un costo adicional y está sujeto a las variaciones climáticas para no chocar con la temporada de lluvias. El programa de traslado les entregó varias herramientas comunes: pala, pico, machete, hacha, pero no sierra mecánica. La Sub Zona Agraria les prestó algunas sierras, pero

6 Dos años después, la Colonización mandó construir un puente sobre el río Frijol, para dar pase hacia las tierras ganaderas, pero por la crecida del río en la temporada de lluvia, el puente quedó inutilizado. éstas se inutilizaron en los primeros días de trabajo, porque los campesinos de la sierra no sabían usarlas. Por esas dificultades, varias familias se desalentaron y optaron por abandonar el programa. De las 83 familias que llegaron a Zangapilla, con un total de 186 miembros, disminuyó a 66 familias en Megote. Ver en el terreno las dificultades para abrir campos de cultivo produjo la primera merma de ancashinos.

Para encontrar alguna solución a la continuidad alentadora de los damnificados, nos vimos obligados a proponer que el Banco de Fomento Agropecuario (BFA) de Tingo María les haga un préstamo a cada familia, para resolver el problema del desbosque. Esa propuesta tuvo sus dificultades por la desconfianza de su devolución. Tuvimos que apelar a la intermediación de la Primera Dama de la Nación y representante de la JAN, para que finalmente el BFA aceptara otorgarles un préstamo de 1,500 soles a cada familia, para afrontar la primera campańa de siembra de arroz, recomendada por los técnicos. Con el aval de la Zona Agraria, 53 campesinos de los 66 que llegaron a Nuevo Paraíso, recibió ese préstamo, 13 campesinos prefirieron no asumir esa deuda. De los 53 favorecidos, sólo 37 destinaron el dinero para el desbosque y sembrar arroz, a razón de una hectárea cada uno; los otros 16 usaron esos fondos para emprender el retorno a sus pueblos de la sierra.

Las dificultades continuaron para los damnificados de Nuevo Paraíso. La siguiente experiencia la tuvieron en la primera campaña de siembra de arroz, en los campos abiertos con evidentes dificultades. Recibieron semilla para la siembra, como querían los ingenieros y tuvieron que enfrentar nuevas adversidades. El resultado de esa primera siembra de arroz fue un fiasco. De los 37 agricultores, sólo cinco campesinos cosecharon dos quintales de arroz cada uno, otros nueve cosecharon escasamente un quintal; el resto no cosechó nada. La única ventaja de esa inversión fue haber abierto un campo de cultivo. Frente a este fracaso, como responsables del traslado, hicimos notar a la administración de la Colonización, que la campaña de arroz no había contado con una dirección técnica profesional competente. Los campesinos fueron atendidos sólo por los extensionistas. El fracaso de esta primera experiencia se debió a la falta de dirección técnica especializada.

En esta etapa concluyó nuestra participación con los damnificados. Al retirarnos, les recomendamos 
que cultiven lo que la gente de la zona cultiva. Así lo hicieron en los ańos siguientes. Sembraron yuca, camote, maíz, plátanos y papayas, con los que sí tuvieron éxito los que se quedaron allí. Tenían para comer con los frutos de sus propios esfuerzos. Durante la promoción del traslado, don Alberto Irigoyen les había dicho dos cosas que sí lo experimentaron en forma directa: que la papaya no necesita ser sembrada, basta tirar las pepitas por los caminos, allí nacen las plantas y abundan las papayas; tampoco es necesario pescar, cuando las cochas se van secando en el verano, los peces están para cogerlos con las manos. Esas realidades lo experimentaron ellos mismos en la «tierra prometida». Intercambiar experiencias con la gente de Uchiza les sirvió mucho para adaptarse lentamente en la cultura cotidiana de la selva alta.

Alegría espiritual y corporal. Por nuestra parte, hicimos todo el esfuerzo para darle estabilidad a los damnificados en su nueva residencia. Queríamos que el programa tenga éxito y que para eso debían aprender la cultura selvática, con el contacto de la gente del lugar. Con esa finalidad promovimos varias actividades. Con la participación de 20 personas representativas hicimos una visita de buena vecindad al pueblo de Uchiza, localizada a unos $10 \mathrm{~km}$ del campamento. Las autoridades y el pueblo de Uchiza nos recibieron con mucho afecto, por lo que nos quedamos allí dos días. Vimos que era un pueblecito muy parecido a los de la sierra, con su plaza, sus calles a los cuatro costados, su municipio y su comisaría. Las viviendas eran con paredes de adobe, de madera y algunas de material noble, pero todos con techos de teja, muy distinto a las de Tocache. Acordamos con las autoridades para que nos hagan una visita de cortesía, que cumplieron dos meses después. Para regresar al campamento de Nuevo Paraíso, nos pusieron un guía, quien nos hizo llegar caminando en poco más de una hora, en línea directa por el bosque.

Por otro lado, algunos campesinos nos mostraron su preocupación por escuchar una misa. Con Sonia fuimos en busca de un sacerdote que vivía en una cooperativa, al otro lado del río. Con mucho gusto aceptó viajar al campamento para oficiar una misa el siguiente domingo. Era un sacerdote irlandés, que hablaba bien el castellano. Ofició una misa en la casa comunal, llena de gente y repartió hostias a la mayoría de feligreses. Después de la misa organizó un ameno diálogo con los damnificados. Les felicitó por la aventura de trasladarse a la selva, como él también lo había hecho. Les preguntó, qué es lo que más anhelan en esta nueva tierra. Varios contestaron diciendo que deseaban construir allí una iglesia. El sacerdote les contestó amablemente, argumentando que estaban equivocados en ese propósito, cuando recién se están instalando y no tienen todavía las comodidades necesarias, que son más importantes para las familias. Les dijo que para hacer misa no se necesita una iglesia, se puede hacer en campo abierto o en la casa colectiva como la que ya tienen. Luego les recomendó que aspiren a ser buenos agricultores, que produzcan alimentos para el consumo y comercialización, que organicen una armoniosa comunidad con todas las familias que han llegado a este hermoso paraíso. Meses después, cuando ya no estábamos con ellos, nos enteramos que el padre irlandés fue varias veces a oficiar misa en el campamento de los damnificados. Desde luego, lo hacía al aire libre.

Cuando los jóvenes damnificados nos pidieron algo de diversión, para no fugarse los fines de semana a Nuevo Progreso o a Aucayacu, les organizamos también una bulliciosa fiesta en el campamento. Con ese fin, enviamos a Ofelia para que indague y comprometa a una orquesta en Tingo María, para venir a animar una fiesta en la estancia de los damnificados. En su condición de tingalesa, ella y su hermano, lograron comprometer la colaboración de dos conjuntos musicales, sin costo alguno, con la única condición de contar con movilidad de ida y vuelta. Pudimos cubrir esos requerimientos con el apoyo de autoridades e instituciones de Aucayacu y de Tingo María. La fiesta se realizó un sábado por la noche. Con anticipación, preparamos un estrado en la plaza del campamento; se hicieron las invitaciones a los amigos de Uchiza, Puerto Progreso y de cooperativas aledañas. La fiesta resultó todo un acontecimiento. Asistió mucha gente de los pueblos vecinos, vinieron incluso de Tingo María, unos caminando, otros con el volquete y el tractor disponible. Las mujeres prepararon comida para vender esa noche y los jóvenes se ingeniaron para traer cerveza y gaseosas de Puerto Progreso. A las siete de la noche se dio comienzo a la fiesta, con estruendosos sonidos de instrumentos musicales electrónicos, generados con baterías, en medio de la selva, que probablemente asustaron a las aves, monos aulladores y otros animales que viven en los árboles del entorno. Todo el mundo se puso a 
bailar con alegría. La fiesta sirvió, además, para estrechar muchas amistades con gente de Uchiza y Puerto Progreso, los más cercanos. Las orquestas y sus cantantes se quedaron hasta el amanecer del domingo.

A pesar de estos esfuerzos, los resultados generales fueron poco alentadores. En mi caso personal, me involucré en este proyecto con mucho entusiasmo, por influjo de mi profesor y paisano Mario Vásquez. Sonia como asistenta social y Ofelia como educadora familiar, contribuyeron con mucha voluntad y profesionalismo en el tratamiento de los damnificados. La Oficina de la Colonización tuvo buena voluntad para apoyar el asentamiento en Megote, con la construcción de caminos de penetración hasta las parcelas, puente sobre el río Frijol, apoyo en diversas etapas de la aclimatación, traslado y entrega de lotes de terreno a cada familia, pero falló en el apoyo técnico. La mayoría de profesionales de la Sub Zona Agraria eran ingenieros civiles, pocos agrónomos, que no eran proclives al trabajo de campo o no fueron destinados para apoyar a los damnificados. Esa ausencia de orientación técnica a los damnificados, provocó el fracaso de la primera campaña de siembra de arroz. Esas deficiencias tuvieron sus consecuencias en las decisiones de los emigrantes ancashinos. Nos enteramos que dos años después, el número de damnificados en Nuevo Paraíso había disminuido a 26, dedicados a policultivos de la zona, peones de campesinos pudientes y de cooperativas del valle, negocios diversos en el mismo campamento o en Aucayacu. Cuando lo visitamos en 1974, quedaban sólo 17 ancashinos. Las tierras agrícolas y ganaderas entregadas a los damnificados fueron ocupadas mayoritariamente por campesinos de la zona, quienes asumieron la deuda al BFA. Por esos años llegaron los colombianos a Nuevo Paraíso y lo convirtieron en "paraíso de la coca" para destinarlo al clorhidrato de la cocaína. Este es el resumen del traslado de damnificados de Ancash a la Colonización de Tingo María.

\section{La segunda campaña: ganadería en Chontayacu}

La colonización Tingo María-Tocache-Campanilla requería de mayor cantidad de campesinos dentro de su proyecto. Los técnicos de esa entidad, tenían la convicción de que el terremoto de Ancash ofrecía las condiciones necesarias para promocionar más damnificados para ser trasladados hacia la colonización. Propusieron realizar una segunda campaña de incentivación de damnificados de Ancash para cubrir el programa de crianza de ganado cebú en el sector de Chontayacu. Con ese propósito, la Colonización, a través de la IX Sub Zona Agraria, mandó desboscar 100 ha de terreno cerca de la desembocadura del río Chontayacu y sembrar pasto mejorado con los fondos del préstamo BID. El sector Chontayacu está situado a poca distancia del distrito de Uchiza. Asimismo, construyeron allí un campamento para albergar 50 familias ganaderas. Este proyecto ganadero difería sustancialmente del asentamiento campesino en Megote. La adjudicación de las 100 ha de tierra sería en forma asociativa y no en lotes individuales como en el caso de Megote. Por lo mismo, las 50 familias de Chontayacu, formarían una cooperativa de producción.

Para realizar el trabajo de promoción para Chontayacu nos convocaron a Lima. Por entonces, la Sub Zona Agraria de Aucayacu, nos había contratado, a Sonia, Ofelia y a mí, para continuar en la colonización, bajo su dependencia, porque nuestros contratos con la JAN habían concluido en diciembre de 1970. Nuestro trabajo en la colonización consistía en realizar diversas acciones de carácter social en todo el valle, incluyendo a los damnificados de Nuevo Paraíso. Por directiva del jefe de la IX Sub Zona Agraria, tuvimos que constituirnos a Lima. En la oficina de la JAN nos volvimos a encontrar con Alberto Irigoyen, quien era funcionario del Ministerio de Agricultura. Nos presentaron también a la señorita Lucía, socióloga sanmarquina, quien se integró al grupo para el segundo reclutamiento de damnificados de Ancash, esta vez para ser trasladados con destino al programa ganadero de Chontayacu.

\section{Otra vez en Yungay y Bolognesi}

Nos asignaron nuevamente la misma camioneta y el mismo chofer para cubrir el trabajo de promoción e inscripción de campesinos. Acordamos con los funcionarios del gobierno, volver a las mismas regiones anteriormente visitadas: Callejón de Huaylas y provincia de Bolognesi. Esta vez, nos fue más sencillo movilizarnos hacia los dos destinos, porque ya los habíamos recorrido y porque Irigoyen y yo conocía- 
mos en detalle los dos espacios. Nuestro cronograma de trabajo, contemplaba realizar la promoción e inscripción en el mes de mayo de 1971 y el traslado a la colonización el mes siguiente. Nos dirigimos primero al Callejón de Huaylas, visitando Huaraz, Carhuaz y Yungay. Un año después del terremoto, los pueblos del Callejón de Huaylas ya se habían restablecido parcialmente de los efectos del sismo. Los escombros dejados por la violencia telúrica habían sido limpiados con maquinaria pesada, por lo que las calles ya eran transitables, pero mucha gente vivía en casas prefabricadas en los alrededores de las ciudades, proporcionadas por la Comisión de Reconstrucción y Rehabilitación de la Zona Afectada (CRYRZA), creada por el gobierno. En Huaraz, los desmontes estaban siendo acumulados fuera de la población, con la finalidad de construir un nuevo Huaraz, proyectado con visión moderna. En Carhuaz, se procedía a reconstruir la misma estructura de la población, refaccionando los edificios públicos y las viviendas familiares. Yungay, seguía luciendo el barro endurecido por donde corrió el lodo del aluvión. En lo que era la antigua plaza, seguían de pie las cuatro palmeras solitarias que resistieron al ímpetu del aluvión, mientras que las dos hileras de nichos del cementerio, con el Cristo en su cima, se mantenían intactas, pero las hileras inferiores no daban muestras de ser rehabilitadas. Fuera de la población, las tierras cultivables bajo riego, reverdecían con nuevas siembras, por haberse restablecido los canales de riego, también siniestrados por el terremoto.

Nuestro trabajo de promoción comenzó en Yungay. Se habían habilitado locales para la atención de las autoridades provinciales y también tenían amplios ambientes hechos de madera prefabricada proporcionada por CRYRZA. En uno de esos ambientes nos recibieron y allí procedimos a convocar reuniones por dos días consecutivos. Alberto Irigoyen, experto en motivar a la gente, se lucía en cada reunión, explicando con lujo de detalles las bondades del valle del alto Huallaga y las muchas posibilidades de forjarse un mejor porvenir. Yo le secundaba dándoles a conocer sobre los aspectos sociales del programa y sobre la infraestructura de vivienda y caminos carreteros, preparados por la Colonización. Les explicamos que este nuevo proyecto era para criar ganado importado, organizados en cooperativa. Asimismo, se les informó, que el proyecto incluía el funcionamiento de una escuela primaria para los niños de las unidades familiares. Estas informaciones verbales del proyecto ganadero se repitieron en Carhuaz y en Huaraz.

El resultado no fue muy alentador. La mayoría de las familias ya había entrado a la rutina tradicional del cultivo de productos agrícolas en sus chacras y la idea de la organización en cooperativa de producción, no les era atractivo para inscribirse en el programa. Otro factor en contra, era que las autoridades provinciales y CRYRZA, requerían mano de obra para un sector de campesinos sin tierras o con pocas tierras. Quienes viajaron fueron principalmente jóvenes sin tierras de cultivo y algunas familias pobres que aceptaron viajar con todos sus miembros. Sin embargo, el total de familias inscritas en las tres poblaciones no pasaba de 40. Fijamos una fecha del mes de junio para pasar a recogerlos, para transportarles hacia Lima y luego a la colonización.

Completamos el trabajo viajando a la provincia de Bolognesi. Escogimos visitar tres localidades donde hubo mucha destrucción por el sismo de 1970: Raján, Llipa y Cajamarquilla, comunidades situadas en el sur, cerca de la frontera de Bolognesi (Ancash) con Cajatambo (Lima). La carretera afirmada de Ocros a Raján, construida por la empresa minera de Chinches ${ }^{7}$, nos facilitó la entrada a estas localidades. El trabajo de promoción lo hicimos primero en Raján, luego en Llipa y concluimos en Cajamarquilla. De Raján a Llipa pudimos bajar por la carretera rehabilitada por la empresa minera, pero el tramo de Llipa al puente de Muri, sobre el río Pativilca, seguía interrumpido. El empalme de la carretera de la mina de Chinches a Cajamarquilla, había concluido en esos días, con el apoyo de la empresa y la inauguración estaba programada para el día que nos tocaba visitar esa localidad, por lo que las autoridades no permitieron que entráramos con la camioneta. La promoción lo tuvimos que hacer viajando a pie los cinco $\mathrm{km}$ de distancia. En estas comunidades éramos conocidos por ser naturales de la provincia. Esas relaciones coadyubaron nuestro trabajo, por lo que tuvimos relativo éxito. Sus autoridades colaboraron eficientemente en fomentar las reuniones en sus salones comunales, refaccionados después del sismo, pero las iglesias y muchas casas familiares seguían inhabitables en las

7 Era una empresa de mediana minería, que explotaba cobre y plata. En su sede de Mala se llamó Empresa Minera Condestable S.A. 
tres poblaciones. Encontramos mayor destrucción en el poblado de Llipa, por estar situado en una ladera. Se inscribieron en total 45 familias de estos pueblos.

\section{Con destino a Chontayacu}

A mediados de junio fuimos a recoger a las familias inscritas para el proyecto ganadero de Chontayacu. En nuestros registros figuraban 89 inscritos en total, pero a la hora de la verdad sólo se animaron 32, la mayoría sin familia. Los buses asignados para ambas rutas regresaron casi vacíos, 14 del Callejón de Huaylas y 18 de la provincia de Bolognesi. Con este contingente no pudimos cubrir las 50 familias que se requerían para el proyecto ganadero. En Lima alojamos al grupo en los ambientes de la JAN y dos días después partimos hacia la colonización en un solo bus, más la camioneta que nos acompańaba. No estaba prevista la temporada de aclimatación para ellos, el viaje fue directo a Chontayacu. Llegamos a la altura del campamento al caer la tarde. Dos botes con motor fuera de borda esperaban en la orilla del Huallaga para vadear con la gente al campamento, situado en la margen izquierda. Los campesinos se alojaron en tres ambientes hechos de madera y techos de paja. Se les proveyó de utensilios de cama, que fueron colocados en tarimas de chonta. En otros ambientes estaban instalados los trabajadores contratados por la colonización, encargados del desbosque y del sembrío de pastos en las 100 ha prometidas.

El día siguiente, tuvimos la primera reunión de bienvenida con los campesinos y los funcionarios de la Sub Zona Agraria de Aucayacu. El ingeniero responsable les dio a conocer los objetivos del proyecto, la organización de una precooperativa de producción y les mostró los campos ya desboscados donde pastaría el ganado. Luego se discutió el nombre del campamento, que hasta ese día se llamaba Chontayacu. Se propusieron varios nombres, pero no había acuerdo por ninguno. Frente a esa situación, un damnificado propuso que se llame Campamento Lucía, en alusión al nombre de la socióloga de nuestro grupo de motivación. La mayoría estuvo de acuerdo con esa denominación, pero alguien le agregó el de santa, por lo que todos coincidieron en llamarla Campamento de Santa Lucía. Quedó por buen tiempo con ese nombre, luego se alternó con el de Nuevo Progreso, como le denominaron los ingenieros en el proyecto de la precooperativa. A finales de los años ochenta, se construyó frente del campamento ganadero de Santa Lucía, una Base Militar-Policial, en la margen derecha del Huallaga. Fue financiada y mantenida por el gobierno de los EE.UU. a través de la DEA en el Perú, con personal militar y policial peruano. Su construcción y equipamiento moderno, con campo de aterrizaje de helicópteros, tenía por objeto enfrentar la producción de droga y contener al movimiento subversivo senderista en la región del alto Huallaga. Esa Base Militar ${ }^{8}$ también se llamó Santa Lucía. Para entonces, el proyecto ganadero formado por este grupo sufrió deterioro, por deserción de sus trabajadores y años después se desactivó definitivamente.

Nuestra participación concluyó con el traslado de las 32 familias damnificadas de Ancash al campamento ganadero de Santa Lucía. La conducción del proyecto corrió por cuenta de la misma Colonización. Irigoyen retorno a su centro de trabajo en Lima, Lucía también, y yo volví a retomar mis labores sociales en la sede de la Sub Zona Agraria de Aucayacu. El personal asignado al proyecto ganadero tuvo que cubrir el número adecuado de campesinos para formar la precooperativa, promocionando a gente sin tierra de la misma zona y aceptando a algunos aventureros de la sierra que llegaban al valle en busca de oportunidades. Con ellos se completaron los 50 miembros, que se dedicaron a hacer corrales, tender alambrados y a seguir sembrando pasto mejorado, bajo la dirección de un ingeniero. Con ellos se formalizó la Cooperativa de Producción Ganadera de Nuevo Progreso. Fue nombrado como presidente del Consejo de Administración un campesino de Cajamarquilla, quien se quedó allí por más de diez años. Integró la comisión que viajó a Centro América para comprar un lote de vaquillonas y sementales de raza cebú. La trajeron en barco hasta Lima y de Lima la transportaron en camiones hasta Santa Lucía. Nos enteramos que a fines de 1972, el 50\% de ancashinos había retornado a sus pueblos de origen. Pero el proyecto continuó con campesinos selváticos y personal asalariado, hasta que el narcotráfico y la guerra interna de los años ochenta, la desactivaron por completo. Desde ese entonces, el nombre de Santa Lucía quedó

8 Esta moderna Base Militar-Policial se mantuvo hasta fines del 2005, hasta que su personal se trasladó a Tingo María, para conducir desde allí la política de erradicación del cultivo de coca. 
sólo en la Base Militar, que también sobrevivió hasta el primer quinquenio del nuevo siglo.

\section{Política de colonización de la selva en el Perú}

El traslado de familias damnificadas de Ancash a la selva alta de Tingo María se inscribe dentro de la añeja política gubernamental de colonización de la selva, que viene desde el siglo XIX. Diferentes gobiernos han promovido la colonización de ceja de selva con la finalidad de extraer los abundantes recursos naturales existentes en esa región. También por explotar la tierra virgen para producir bienes alimenticios para comerciarlos hacia los centros urbanos. Por los cronistas coloniales tenemos información de que los incas destacaban mitimaes para cultivar coca, ají, frutales y también para obtener plumajes de aves ornamentales. El Perú republicano fue más allá, se propuso desarrollar en la selva alta la producción de bienes de consumo interno y de exportación, como café, cacao, frutales, caucho, además de coca, para el rentable negocio de su consumo tradicional. Desde mediados del siglo XIX, los sucesivos gobiernos, promovieron la ocupación de tierras de montaña, mediante la emigración campesina permanente hacia Chanchamayo. Desde esos tiempos se formaron en ese sector de la selva dos formas de propiedad: haciendas productoras de café y cańa de azúcar y pequeńas propiedades para cultivar productos de consumo local: yuca, maíz y frutales. Por entonces no había carretera. Los productos comerciales salían en acémilas por caminos de herradura hacia Tarma.

Migración extranjera. La promoción de asentamientos de inmigrantes europeos hacia la selva, también viene del siglo XIX. La primera experiencia data de 1857, mediante un contrato firmado por el presidente Ramón Castilla y el promotor alemán Cosme Damián Shultz. El primer grupo de 297 tiroleses austriacos llegó al Perú en 1847 para ser trasladados a Pozuzo ${ }^{9}$ dos ańos después. Ellos formaron un pueblo muy peculiar, de estilo alemán y desarrollaron allí una cultura propia, en medio de la selva. Se dedicaron a cultivar diversos productos y a criar ganado vacuno para su autosostenimiento. Una nueva olea-

9 A falta de carretera, los tiroleses viajaron a Pozuzo a caballo y a pie. La carretera de Tarma a Chanchamayo se construyó en los años veinte en aplicación de la ley de Conscripción Vial de Leguía. da de alemanes se sumó a finales del siglo. Con ellos se fundaron las ciudades de Oxapampa y Villarrica, para dedicarse al cultivo de café y otros productos comerciales.

Un grupo de 50 italianos de extracción campesina, ocupó extensas tierras a escasos $30 \mathrm{~km}$ de la ciudad de Tingo María en el alto Huallaga, en 1959, durante la gestión de Manuel Prado. El gobierno peruano le otorgó una concesión de 15,000 ha para convertirlo en un complejo agroindustrial. Este grupo de europeos, formó con esas tierras la Sociedad pro Acciones Italo-Peruana Agrícola Industrial (SAIPAI). En sus amplios terrenos se dedicaron a cultivar café, cacao, té, criar ganado y a explotar madera en un aserradero. Captaron mano de obra, con campesinos sin tierra y con campesinos enganchados de los pueblos de Huánuco. Con ellos se formó Pueblo Nuevo, un asentamiento ubicado dentro de ese complejo agroindustrial. La colonización de SAIPAI tuvo éxito en los primeros años de gestión. Incluso construyeron una línea férrea de Pueblo Nuevo hasta el río Huallaga para transportar sus productos hacia Tingo María y de allí enviarlo en camiones hacia Lima. Pero la construcción de la carretera de Tingo María-Aucayacu, impulsado por el presidente Belaúnde, les fue más favorable, porque les permitió transportar sus productos directamente desde su propio campamento. Según las indagaciones de Bedoya (1981), entró en crisis por la deserción de familias italianas. Se mantuvo como empresa privada, con mano de obra asalariada, hasta que en los años sesenta fue invadida por campesinos sin tierra, por lo que tuvo que ceder una parte de la concesión. Con la reforma agraria de 1969, SAIPAI fue convertida en Cooperativa de Producción «Perú Oriental». Cuando lo visitamos en 1970, conocimos a la última familia italiana que vivía allí. Todos los demás se habían retirado a Lima.

Colonos de la sierra. El flujo más dinámico de la migración serrana hacia la selva alta se ha producido en el siglo XX. Este fenómeno social ha ocurrido en toda la franja de ceja de selva peruana: el alto Huallaga en Huánuco y San Martín, Chanchamayo en Junín, Pichari en Apurímac y Ayacucho, la Convención y Lares en Cusco, Pucaramayo y Tambopata en Puno. La construcción de carreteras de penetración hacia la selva, iniciada en los años veinte, abrió las puertas de la Amazonía para la migración hacia el rupa rupa. Ese mismo proceso se dio con la construcción de la ca- 
rretera de Huánuco a Tingo María, que años después continuó con la carretera hacia Pucallpa. Fernando Belaúnde, desde su primer periodo, impulso la construcción de caminos carreteros en todo el Perú y puso en ejecución la carretera marginal, con fines de integración. Esos planes viales ampliaron el horizonte de las colonizaciones a lo largo de la ceja oriental del Perú.

Martínez (1990), clasifica las colonizaciones de ceja de selva en dos categorías: colonizaciones espontáneas y colonizaciones dirigidas. El modelo espontáneo ha consistido en la emigración espontánea de gente de la sierra hacia ese amplio valle, para dedicarse a la agricultura, por ocupación informal, adjudicación o por compra, un espacio de tierra. Esta práctica comenzó en el siglo XIX, pero ha tenido mejor desarrollo en el siglo XX. Las colonizaciones dirigidas han consistido en procesos de traslado de familias al valle de Tingo María, promovidas expresamente por los gobiernos. En este segundo modelo, el Estado les ha adjudicado tierras para dedicarlo a la agricultura y/o criar ganado. Con este propósito se han dado distintos dispositivos legales para afirmar la propiedad de la tierra. En el caso de Tingo María, las colonizaciones espontáneas tienen larga data. El valle estuvo poblado desde antiguo por diferentes grupos étnicos, como los tingaleses, tulumayos, carapachos, callisecas, a quienes se les llamaba chunchos. Fueron franciscanos los que fundaron la primera población de Tingo María en 1632, en su propósito de catequización de chunchos. Después fundaron Uchiza, a $170 \mathrm{~km}$ al norte. Sobre estos núcleos poblacionales se fueron incrementando forasteros de la sierra. Desde esos tiempos se ha producido una lenta emigración, principalmente serrana, ocupando primero, espacios cercanos a Tingo María y desde mediados del siglo XX, ambas márgenes del Huallaga, para cultivar coca, maíz, yuca, plátanos. Hasta los años sesenta, había en este valle tres tipos de ocupación: grandes haciendas cafetaleras, medianas haciendas y terrenos familiares con 10 a 15 ha. Los antiguos grupos nativos se fueron extinguiendo por alejamiento a la selva baja, enfermedades contraídas, etnocidio de los caucheros y explotadores de madera. Quedan aisladas familias ya sin identidad étnica que residen en el fondo del bosque, otros se han mestizado con los emigrantes.

Colonizaciones dirigidas. Durante el siglo XX se ha producido un notable proceso migratorio al valle de Tingo María, tanto en su forma espontánea como en la modalidad dirigida. El antecedente más antiguo que le dio formalidad legal a la colonización de esta parte de la selva, es la ley 8687, que fue promulgada en julio de 1938, al amparo de la ley de conscripción vial. Ese mismo año, cuando se construía la carretera hacia Pucallpa, el gobierno dispuso la apertura de «... la colonización de Tingo María, como centro oficial de colonización, entregándose a cada colono una hectárea para siembra de yuca o plátanos, según el tipo de tierra, una casa de madera, algunos implementos agrícolas y 1,000 soles, ... en los alrededores de la actual Tingo María» (Citado por Martínez, 1990:66). Los terrenos de las colinas cercanas de esta ciudad, que lucían con plantaciones de coca en 1970, antes de su posterior erradicación, eran adjudicaciones de los años treinta. Desde esos tiempos, los campesinos de la sierra, fueron ocupando tierras en Tingo María, Monzón y Uchiza. Una de las características más comunes era, como sostiene Aramburú (1978), que los campesinos de la sierra bajaban a la montaña sólo por temporadas, tanto como peones de las haciendas, que necesitaban mano de obra durante las cosechas de café o de cacao, cuanto como mejoreros y posesionarios precarios de parcelas para cultivar yuca, maíz y plátanos.

Con la finalidad de incentivar la migración permanente a este valle, el gobierno central tuvo que crear una colonización institucionalizada, bajo control estatal. En 1964, el gobierno dio nacimiento a la Colonización de Tingo María-Tocache-Campanilla, un proyecto gubernamental, con fondos del Banco Interamericano de Desarrollo (BID) ${ }^{10}$. Con esa inversión, se proyectó colonizar 108,000 ha de bosques, con estudios técnicos de clases de tierras, construcción de infraestructura vial, asentamiento y reasentamiento de 4,220 familias. La idea de los técnicos estaba orientada a que las familias campesinas que se trasladen al valle, tengan las comodidades e infraestructura preparada por el organismo colonizador (La Oficina Nacional de Reforma Agraria ONRA primero y por la Dirección General de Reforma Agraria y Asentamiento Rural DGRAAR después). En esa época comienza la captación de grupos de familias po-

10 La financiación de la Colonización de Tingo María-TocacheCampanilla contó con el préstamo 98 del BID. De acuerdo al convenio, el BID aportó 15 millones de dólares, la contrapartida peruana 10 millones. 
bres de las ciudades para ser conducidas hacia Tingo María. En los años cincuenta, ya se había hecho un ensayo de traslado de familias a Tingo María, alentados por los técnicos del presidente Manuel Odría.

$\mathrm{El}$ antecedente más temprano de colonización dirigida se produjo en 1960, cuando se organizó el traslado de un grupo de 80 familias pobres de los barrios periféricos de Lima, principalmente del Rímac, hacia el alto Huallaga. La finalidad era entregarles tierras para colonizar la selva alta de Tingo María, con los auspicios y el apoyo directo del Estado. Conducido por técnicos del Ministerio de Agricultura, este primer grupo de colonos fue ubicado en La Morada, situada a $95 \mathrm{~km}$ de Tingo María, margen izquierda del Huallaga. Con ese mismo propósito, los gobiernos de esa década, promovieron el envío dirigido de otros grupos de campesinos pobres y sin tierras de distintas provincias, como de Arequipa y de Piura, que fueron ubicados entre las localidades de Puerto Progreso y Tocache, margen derecha. Los damnificados ancashinos llegaron también a esta colonización en 1970 y 1971, de cuyos detalles ya nos hemos ocupado líneas arriba. En todos los casos de migración dirigida, los tipos de adjudicación de tierras son específicos: La Morada y Nuevo Paraíso, adjudicatarios individuales de tierras agrícolas y ganaderas; los de Arequipa, Piura y Nuevo Progreso o Santa Lucía, adjudicación asociativa de cooperativas de producción. En cambio, los que han migrado espontáneamente, han ocupado tierras en distintas formas y se han juntado entre paisanos para fundar una población con el nombre de su región de origen, como el caso de Nueva Cajamarca, formada por cajamarquinos.

Lo que acabamos de comentar, nos demuestra que los gobiernos del Perú, desde la fundación de la República, han puesto la mirada hacia la selva con fines de colonización. Con ese objeto se han dado disposiciones legales, alentando la ocupación de toda la ceja de selva para explotar la tierra disponible. Los movimientos campesinos de los años sesenta, con tomas de tierras y exigencia popular de reforma agraria, avivó la propuesta de las clases dominantes de colonizar la selva ${ }^{11}$. La construcción de carreteras de penetración ha contribuido en el desarrollo de las colonizaciones. En la actualidad, el valle del alto Huallaga

11 Es famosa la frase pronunciada por el entonces primer ministro Pedro Beltrán: «No es necesario quitar la tierra a quien la tiene, cuando en la selva nos sobran tierras para los que no la tienen». está muy bien poblado por familias que se han asentado permanentemente. A lo largo del valle, se han formado varias poblaciones importantes, con gente que trabaja la tierra, que se dedican a diversos negocios. El tráfico por la carretera marginal es intenso, con camiones que sacan plátanos, yuca, pińa, papaya, madera, madera prensada y otros productos industriales que se procesan. Ahora cuentan con un moderno puente en Tocache y en Uchiza. De allí viene el aceite de palma procesado en EMDEPALMA. Los asentamientos campesinos en toda la colonización de Tingo María, incluyendo los de Nuevo Paraíso y de Santa Lucía, han sufrido transformaciones significativas durante las décadas del ochenta y noventa, tanto por el narcotráfico como por la guerra interna. Por efecto de esos dos problemas de fines del siglo pasado y por otras causas, ya no hay familias ancashinas en Nuevo Paraíso ni en Santa Lucía. Casi todas las familias ancashinas han retornado a sus lugares de origen. Hasta donde tenemos noticia, una sola familia se ha quedado en el valle, la familia Reyes-Cruz, migrantes de Chilcas que fueron a Megote. Ellos residen en Aucayacu dedicado a negocios de consumo doméstico en tienda particular. Es la única excepción.

\section{Epílogo}

Sin la menor duda, el terremoto del 31 de mayo de 1970 en Ancash dejó a miles de familias en el desamparo, por la pérdida de sus bienes. No sólo perdieron a sus familiares, parientes y paisanos, perdieron sus casas, sus enseres domésticos, canales de riego y otros recursos sociales y familiares. El gobierno central quiso paliar esta situación, apelando al programa de traslado de damnificados a la colonización de Tingo María, a fin de que esas familias construyan una nueva vida en la selva, con el apoyo gubernamental. Las familias que aceptaron adscribirse a este programa, fueron mayoritariamente damnificados por el sismo, pero también se inscribieron familias sin tierras y algunos aventureros que aspiraban conocer el lejano y tropical ambiente de la selva. En esas circunstancias, la burocracia limeña proyectó trasladar 300 familias ancashinas a la colonización de Tingo María, como parte del asentamiento y reasentamiento de 4,220 familias campesinas. No se pudo cumplir con esta cantidad de aspirantes ancashinos hacia la Colonización. 
En las dos campañas promovidas, se inscribieron 320 familias, pero sólo 124 familias decidieron finalmente viajar a la colonización: 89 para Megote y 35 para Chontayacu.

La administración de la Colonización de Tingo María-Tocache-Campanilla, tenía previsto el asentamiento de 250 campesinos en Megote y de 50 en Chontayacu. El primero era un proyecto agrícola-ganadero de adjudicación individual (familiar) y el segundo era exclusivamente de fomento ganadero, bajo organización y adjudicación cooperativa. En ambos proyectos, la colonización cumplió con la construcción de la infraestructura vial y la entrega de parcelas: 10 ha para los agricultores y 40 ha para los ganaderos, en el caso de Megote; la entrega de 100 ha de terrenos desboscados, con siembra de pastos mejorados y viviendas para los de la cooperativa de Chontayacu. Lo que no cumplió la colonización es en la asistencia técnica especializada a los agricultores y ganaderos en Megote y también en Chontayacu. El fracaso de la primera campańa de siembra de arroz en Megote se debió a la ausencia de dirección técnica. Los extensionistas hicieron lo que podían, a falta de agrónomos especializados en cultivos tropicales. Tampoco se cumplió con entregar el ganado prometido a los ganaderos de Megote. Se avanzó en el desbosque parcial y siembra de pastos, pero el ganado no llegó nunca. En Chontayacu, ocurrió lo mismo: se trajeron los cebús de Centro América, pero faltó la dirección técnica en el manejo de ganado de difícil comportamiento, muy diferentes al ganado tradicional de los pueblos andinos. La colonización contaba con un solo ingeniero veterinario para atender a la ganadería de todo el valle. La llegada de narcotraficantes colombianos y peruanos a esa zona, cambió todo el panorama. Se agravó aún más, con la insurgencia senderista y la contrainsurgencia militar-policial. En resumen, ningún ancashino se quedó en los proyectos de los dos asentamientos dirigidos.

Participar en el proceso de traslado de damnificados ancashinos a la Colonización de Tingo María fue para mí una experiencia interesante y aleccionadora. Fue mi primer trabajo como antropólogo. Me involucré a este programa a propuesta de mi profesor y amigo Mario Vásquez, porque se trataba de mitigar en alguna medida los enormes perjuicios provocados por el terremoto en casi todos los pueblos del departamento de Ancash. Me dio la oportunidad de visitar el Callejón de Huaylas y los pueblos de la provincia de Bolognesi, incluyendo a Santiago de Chilcas, pueblo de mis orígenes. En verdad, me enrolé a ese programa con mucha voluntad y carińo. Hicimos el trabajo de motivación, traslado y asentamiento de damnificados, con un equipo de magníficos profesionales. Alberto Irigoyen era un funcionario del Estado, experto en la motivación; Sonia, Ofelia y Lucía eran profesionales recién egresadas y trabajaron como yo, por primera vez en un programa remunerado. Todas ellas hicieron un trabajo excelente, con vocación de servicio y mucha creatividad para compartir y resolver problemas con la gente, especialmente con mujeres, nińas y nińos. Los resultados quedaron a la vista, razón por la cual, fuimos contratados por la Colonización para el año siguiente.

Probablemente por ser jóvenes, llegamos a congeniar con la gente del grupo destinado a Megote. Formamos una comunidad con relaciones casi familiares, en las buenas y en las malas. Hicimos todo lo que estaba a nuestro alcance para que las familias tuvieran comodidad, que no les falte comida, que conozcan el valle y que disfruten de diversiones y entretenimientos. La admirable memoria de Sonia, que guardaba nombres y apellidos, edades, año de nacimiento, números telefónicos, fechas de cada acontecimiento, ayudó mucho en el proceso de aclimatación y de asentamiento en Megote. Los profesores Alzamora de Ocros y Morales de Raján, contribuyeron dando clases a los niños y niñas del grupo; Nonaka de Huanchay y el popular "Curita» de Ocros, actuaron como choferes del volquete y del tractor en Megote. La esposa de Nonaka hizo un buen papel en la organización de mujeres y la hermosa hija de 12 ańos de la pareja Nonaka, fue elegida la primera reina de primavera de los damnificados en Zangapilla. No menos importante fue la contribución del señor Ángeles de Yungay, que aportaba con opiniones acertadas en beneficio de todos. Con este grupo de ancashinos aprendimos asimilar la cultura de la selva. Aprendimos a comer plátanos inguiri, a consumir carne de monte (sachavaca, motelo, sajino, mono maquisapa). Cuando nos visitó una comisión de generales a Megote, le invitamos un almuerzo con cebiche de lagarto, preparado por las señoras de nuestro campamento. Aprendimos todo lo bueno de la vida en la montaña. 
Un par de anécdotas: Uno: Estuvo en nuestro grupo, un señor que se embarcó en Huanchay, no era campesino. Sus paisanos le llamaban el «loco» porque tenía un lenguaje y un razonamiento diferente a los demás. No congeniaba con nadie, andaba solitario y cabizbajo fuera del grupo. Recuerdo que un día le invité tomar un café para conversar. Descubrí que era una persona muy ilustrada en conocimientos culturales de todo tipo y hablaba con mucha propiedad. Tenía buena información sobre filosofía, historia, literatura. En varias ocasiones hemos conversado sobre las guerras mundiales, sobre arte y literatura. Conocía bien las obras de Cervantes, Tolstoi, Vallejo, Ciro Alegría. En una de esas reuniones nos enfrascamos en una animada discusión sobre la música clásica. En varios puntos del diálogo me corrigió, nombre de compositores y corrientes musicales de los grandes maestros europeos. Nada loco, era un Quijote andino «enloquecido» por exceso de lecturas, perdido en un mundo de campesinos profanos. Dos: Viajó también con nosotros a Megote, un señor silencioso y ensimismado, sin ningún protagonismo. En esos seis meses vividos en el valle, nunca me di cuenta quién era esa persona. Estaba mimetizado en el grupo como cualquier campesino. Años después nos volvimos a ver en Lima, en una fiesta costumbrista de los migrantes de Huasta. Me saludó y para recordarme, me dijo que se llamaba Amador Palacios, natural de Aquia y paisano de Mario Vásquez. Recién me di cuenta que Palacios era un personaje importante de la provincia de Bolognesi, violinista de profesión, que formó en 1952, el famoso conjunto «Ritmo Andino de Huasta", bajo la dirección de otro famoso músico, Visitación Laos ${ }^{12}$. Sorpresas tiene la vida, perdí la oportunidad de escribir la biografía artística de este famoso instrumentista ancashino.
12 En 1952, el maestro Visitación Laos fundó al conjunto de cuerdas «Ritmo Andino de Huasta» con tres instrumentistas: Arpa: Visitación Laos; violín de primera: Teobaldo Cano y violín de segunda: Amador Palacios. El conjunto actual tiene siete miembros, se han incluido: un clarinete, una sordina y dos saxos.

\section{Bibliografía}

Aramburú, Carlos (1978). «Las migraciones a las zonas de colonización de la selva peruana. Perspectivas y avances». Ponencia presentada al Seminario sobre Migraciones Internas en el Perú, AMIDEP, Lima.

Bedoya Garland, Eduardo (1981). Latifundio, escasez de mano de obra, enganche y salarios en la ceja de selva. El caso Saipai. Tesis de Magister, PUCP, Lima.

Comité Interamericano de Desarrollo Agrícola (1966). Tenencia de la tierra y desarrollo socioeconómico del sector agricola: Perú. Unión Panamericana, Washington D. C.

MarTínez, Héctor (1990). Las colonizaciones selváticas dirigidas en el Perú. UNMSM, Lima.

Robles, Román (1978). «Asentamientos campesinos en la Colonización Tingo María-Tocache o los mitimaes de nuestros tiempos». En revista Discusión Antropológica, Año 3 (3), UNMSM, Lima.

SÁnchez Garrafa, Rodolfo (2014). Apus de los cuatro suyos. Construcción del mundo en los ciclos mitológicos de las deidades montaña. IEP-CBC, Lima.

Sánchez Garrafa, Rodolfo y Golte, Jürgen (2014). «Sawasiray-Pitusiray, la antigüedad del concepto y santuario en los Andes». En revista Investigaciones Sociales, Vol. 8 (13) UNMSM, Lima.

Valladares, Manuel (2011). Yungay en la memoria. Editorial Pakarina, Lima.

Yauri Montero, Marcos (2000). Leyendas ancashinas. Lerma Gómez EIRL, Lima. 